\title{
Identifying seasonal spatial patterns of crime in a small northern city
}

\author{
Ysabel A. Castle and John M. Kovacs ${ }^{*} \mathbb{D}$
}

\begin{abstract}
Objectives: To explore spatial patterns of crime in a small northern city, and assess the degree of similarity in these patterns across seasons.

Methods: Calls for police service frequently associated with crime (theft, break and enter, domestic dispute, assault, and neighbor disputes) were acquired for a five year time span (2015-2019) for the city of North Bay, Ontario, Canada (population 50,396). Exploratory data analysis was conducted using descriptive statistics and a kernel density mapping technique. Andresen's spatial point pattern test (SPPT) was then used to assess the degree of similarity between the seasonal patterns (spring, summer, autumn, winter) for each call type at two different spatial scales (dissemination area and census tract).
\end{abstract}

Results: Exploratory data analysis of crime concentration at street segments showed that calls are generally more dispersed through the city in the warmer seasons of spring and summer. Kernel density mapping also shows increases in the intensity of hotspots at these times, but little overall change in pattern. The SPPT does find some evidence for seasonal differences in crime pattern across the city as a whole, specifically for thefts and break and enters. These differences are focused on the downtown core, as well as the outlying rural areas of the city.

Conclusions: For the various crime types examined, preliminary analysis, kernel density mapping, and the SPPT found differences in crime pattern consistent with the routine activities theory.

Keywords: Crime mapping, Seasonality, Small city, Spatial point pattern test, Kernel density mapping

\section{Introduction}

Links between weather and the degree of criminal activity that occurs have long been of interest to researchers and policy makers alike (Cohn, 1990; Linning, 2015). Some authors have also studied the influence of seasonality on the rate and location of crime occurrence by integrating weather data with seasonal confounding factors (e.g. de Melo et al., 2018; Linning et al., 2017). These include cultural variables such as holidays and sporting events which tend to recur at the same time each year (Yiannakoulias \& Kielasinka, 2016). Both weather and cultural variables, then, might be expected to contribute

*Correspondence: johnmk@nipissingu.ca

Department of Geography, Nipissing University, 100 College Drive, North Bay, ON P1B 8L7, Canada to crime's similarly seasonal nature (Cohn \& Rotton, 2000; McDowall et al., 2012).

A number of theories try to explain relationships often observed between crime, weather, and other seasonal variables. One is the temperature aggression theory, which posits that heat makes people uncomfortable, and thus more likely to commit acts of aggression (Brunsdon et al., 2009; Cohn, 1990; Ranson, 2014). This theory is limited, as it only relates to crimes involving aggression, and only considers temperature, though other weather variables may also influence crime (Brunsdon et al., 2009; Linning, 2015).

Many recent studies focus on environmental theories of crime such as the routine activities theory. According to this theory, crime is most likely to occur where a potential offender, a suitable target, and a lack of guardianship original author(s) and the source, provide a link to the Creative Commons licence, and indicate if changes were made. The images or other third party material in this article are included in the article's Creative Commons licence, unless indicated otherwise in a credit line to the material. If material is not included in the article's Creative Commons licence and your intended use is not permitted by statutory regulation or exceeds the permitted use, you will need to obtain permission directly from the copyright holder. To view a copy of this licence, visit http://creativecommons.org/licenses/by/4.0/. The Creative Commons Public Domain Dedication waiver (http://creativeco mmons.org/publicdomain/zero/1.0/) applies to the data made available in this article, unless otherwise stated in a credit line to the data. 
occur at the same time and place (Cohen \& Felson, 1979). The times and places in which these circumstances intersect are determined by people's routine activities, which tend to be consistent in the absence of some external disruption (Brunsdon et al., 2009; Cohn, 1990). School holidays are one example, which change the routine activities of both children and their parents or guardians. Factors like inclement weather can also change people's willingness to engage in non-essential outdoor activities. Notably, the occurrence of both of these factors is seasonal, so people's routine activities and the likelihood of crime in certain places should change on a seasonal basis.

Another important theory relating to the spatial distribution of crime is the crime pattern theory (Brunsdon et al., 2009). This theory considers how physical infrastructure shapes people's movements and causes them to converge at certain times and at specific locations (Brantingham \& Brantingham, 1993). At first glance, this theory does not appear to be useful for explaining seasonal patterns of crime. However, infrastructure use appears to change on a seasonal basis in some locations, and may therefore shape seasonal crime rates (Quick et al., 2019).

Clearly, the location of crime might change based on the seasons and other environmental variables. However, several authors have commented that the literature on spatial responses of crime to weather and seasonal variables is limited in comparison to studies focusing on the intensity of crime over time (Brunsdon et al., 2009; Haberman et al., 2018; Linning, 2015). Most spatial studies focus on how crime location changes seasonally rather than under different weather conditions. Some investigate the location of crime in different seasons, without explicitly seeking to assess the similarity of these locations. For example, Ceccato (2005) found evidence to support the hypothesis that crime in Sao Paulo, Brazil, clusters in different locations during different times of year. Szkola et al. (2019) used risk terrain modelling to determine the risk of firearms crime at different times and locations in Baltimore, MD, and found that for most locations, risk varied throughout the year. Other studies do explicitly address similarity in seasonal crime patterns. Andresen and Malleson (2013) sought to determine the degree of similarity in crime patterns occurring between different seasons in Vancouver, BC. They found little similarity between the seasonal patterns of all the crime types they investigated, while another study of Vancouver, conducted with the same technique but at a different scale, found an opposite result (Linning, 2015). Consequently, the question of scale appears to be an important factor for consideration in spatial studies of crime patterns.

Some spatial studies have taken a narrower focus, linking crime seasonality to demographic and economic variables, as well as features of the built environment. Sorg and Taylor (2011) found evidence that the socioeconomic status of neighborhoods in Philadelphia was linked to the degree of seasonality evident in their crime patterns. Breetzke and Cohn (2012) found a similar pattern in South Africa. Haberman et al. (2018) found that certain kinds of criminogenic places, particularly high schools and higher educational institutions, demonstrated a seasonal effect on crime activities. More recently, Quick et al. (2019) conducted a similar study and found that parks, restaurants and bars were associated with seasonal changes in crime rates, whereas high schools were not.

Notably, there are few studies of crime patterns, spatial and otherwise, in smaller urban centers (see Table 1). To the best of our knowledge, the smallest study area used in research related to seasonal spatial patterns of crime is the Regional Municipality of Waterloo, Ontario (Quick et al., 2019), with a combined population of approximately 535,000 in 2016. Additionally, there appear to be no such studies for northern urban centers, which experience greater extremes in seasonal temperatures than the previous study areas. The present study aims to address this gap in the literature. Using five years of calls for service data from the city of North Bay, Ontario, we explore seasonal differences in crime patterns based on crime concentration at the street segment level, kernel density mapping, and Andresen's Spatial Point Pattern Test (SPPT).

\section{Methods \\ Study area}

North Bay is a small city located in northern Ontario, Canada. As a region, northern Ontario is characterized by decreasing population due to outmigration, communities dependent on small businesses focused on resource extraction, and low employment rates (Federal Economic Development Agency for Northern Ontario,

Table 1 Population of study areas from previous spatial studies of seasonal crime patterns

\begin{tabular}{lll}
\hline Paper & Study area & Population \\
\hline $\begin{array}{l}\text { Andresen and Malleson, } \\
\text { (2013) }\end{array}$ & Vancouver, British Columbia & $2,000,000$ \\
Breetzke and Cohn, (2012) & Tshwane, South Africa & $2,200,000$ \\
de Melo et al., (2017) & Campinas, Brazil & $1,154,617$ \\
Haberman et al., (2018) & Philadelphia, Pennsylvania & $1,500,000$ \\
Linning, (2015) & Vancouver, British Colum- & $2,313,328$ \\
& bia; Ottawa, Ontario & $1,236,324$ \\
Quick et al., (2019) & Waterloo, Ontario & 535,000 \\
Szkola et al., (2019) & Baltimore, Maryland & 623,280 \\
\hline
\end{tabular}


2018). While North Bay is larger than many northern communities and thus supports some larger employers, it is no exception to the trends of population decline and low employment rates. For example, the population as of 2016 was 50,396, a decrease of roughly 2000 since 2011, and the employment rate in the same year was $54.1 \%, 5.8$ percentage points lower than in the province as a whole (Statistics Canada, 2017). Further, $17.4 \%$ of residents are considered low income earners, which is three percentage points higher than the provincial average. North Bay is also unusual in its physical characteristics; the majority of its land is forested, with the developed portion of the city comprising a small area between Lake Nipissing and Trout Lake (Fig. 1). Despite the decrease in population, concerns about crime in North Bay have been increasing (BayToday Staff, 2019; Campaigne, 2021; Pickrell, 2020). The city is served by its own municipal police force, the North Bay Police Service (NBPS).

North Bay experiences four distinct seasons. This study adopts a meteorological definition of seasonality, which is based on groupings of months with relatively similar mean temperatures (Trenberth, 1983). Winter is defined as December to February, spring as March to May, summer as June to August, and autumn as September to November. Mean seasonal temperatures for North Bay are presented in Table 2. Summers in North Bay are frequently hot and dry, with temperatures exceeding $30{ }^{\circ} \mathrm{C}$. Winters tend to be cold, with temperatures remaining well below freezing, and frequent snow fall events. Spring and autumn are more variable in their temperatures.

\section{Crime data}

Five years of calls-for-service data, spanning the period from January 2015 to December 2019, were provided by the NBPS. Calls for service include all incidents reported to the NBPS, both directly and through emergency services, as recorded by the computer aided dispatch system (CAD). They represent crime as reported to the police, and so can over or underestimate true crime rates to a degree that varies across the study area (Brower \& Carroll, 2007; Buil-Gil et al., 2021). Despite this, calls for service are frequently used as a proxy for crime data, and have the advantage of temporal specificity (Brunsdon et al., 2009) and inclusion of location data (Andresen \& Malleson, 2013). The North Bay dataset includes the date, time, reported incident type, and coordinates for each call. Some calls also have an associated street address.

No information is available regarding the accuracy of the reported coordinates; however, two anomalous concentrations of calls were visible during initial data exploration. In both cases, these consisted of thousands of calls at precisely the same coordinates. The first occurred at the NBPS's headquarters, and the second on a single street segment in the center of the city. The NBPS service were unable to provide an explanation regarding the cause of these anomalies, but did state that they did not represent real-world crime hotspots. As a result, calls at both the police headquarters and on the affected street segment were removed from this analysis, a total of 13,083 calls, representing $8.7 \%$ of the original dataset.

All call types chosen for this analysis have a relatively high rate of occurrence, and exclude categories such as "911 call" which may not be related to a crime. Incident counts for the chosen call types are presented in Table 3. We chose not to aggregate the calls into categories such as violent vs. non-violent, as different crime types result from different underlying processes and thus display different patterns, which would be obscured by aggregating them into broader categories (Andresen, 2009; Andresen \& Linning, 2012).

\section{Areal units}

The SPPT requires the aggregation of crime incidents into polygons, which may be of various spatial scales. According to Weisburd (2015) a very small proportion of locations in a city will account for a very large proportion of its crime incidents. These micro-places and their associated crime hotspots are generally quite small, consisting of a street segment or a building (Bernasco \& Block, 2011). Accordingly, small areal units should be best able to capture the spatial patterns of crime, being less likely to obscure the actual locations of crime hotspots, or combine multiple hotspots that are in reality distinct. However, smaller areal units will generally contain fewer crimes, making it difficult to determine statistical significance, and leading to volatility in the results (Malleson et al., 2019). In reality, the most appropriate scale for any study will depend on the research question, the crime type being analyzed, and the underlying processes responsible for the distribution of that crime (Hipp, 2007; Malleson et al., 2019).

In addition to concerns regarding the number of incidents in each polygon, it is important to be aware that any analysis relying on aggregation of incidents to polygons is vulnerable to the modifiable areal unit problem (MAUP) (Gerell, 2017; Ratcliffe \& McCullagh, 1999). Both the size of the chosen polygons and the location of their boundaries, which are often arbitrary in nature, can influence the results of analysis. Gerell (2017) found that analyses using smaller polygons generally showed less evidence of the MAUP, as did those performed with administrative boundaries rather than random polygons. Several other authors agree that it is preferable to choose aggregation units which in some way represent the underlying structure and function of the city (Malleson et al., 2019; Vandeviver \& Steenbeek, 


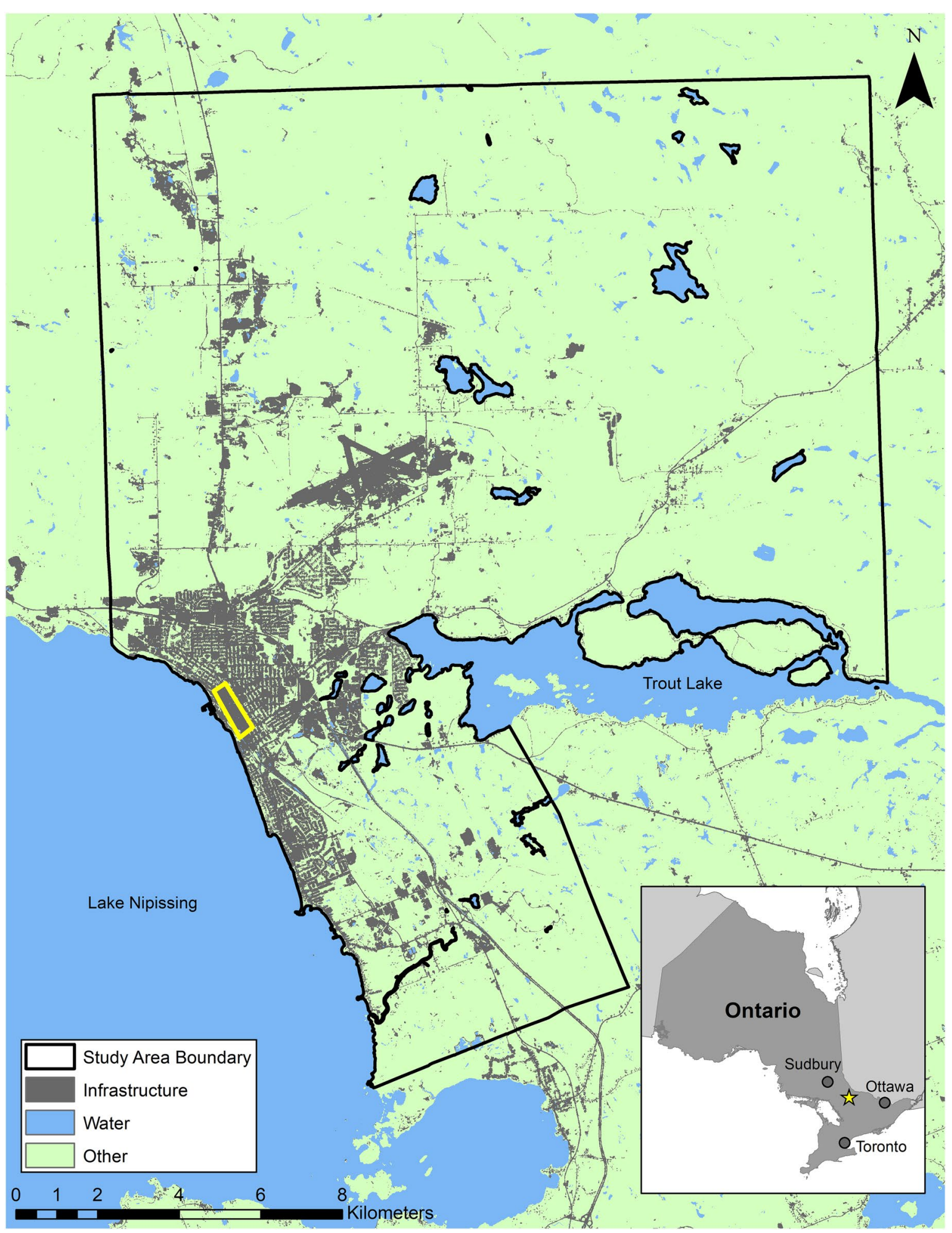

Fig. 1 Land cover in North Bay, June 2018. The location of the downtown core is highlighted in yellow 
Table 2 Seasonal temperatures in North Bay based on 20152019 weather station records

\begin{tabular}{lcrll}
\hline Season & Duration & \multicolumn{3}{c}{ Temperature $\left({ }^{\circ} \mathrm{C}\right)$} \\
\cline { 3 - 5 } & & Mean & $\begin{array}{c}\text { Standard } \\
\text { deviation }\end{array}$ & Range \\
\hline Winter & December-February & -9.8 & 8.3 & $-34.2,13.2$ \\
Spring & March-May & 2.5 & 9.3 & $-25.1,29.5$ \\
Summer & June-August & 17.9 & 4.6 & $2.9,30.9$ \\
Autumn & September-November & 6.8 & 8.7 & $-22.0,28.5$ \\
\hline
\end{tabular}

Table 3 Seasonal counts for calls for police service in the city of North Bay, 2015-2019

\begin{tabular}{llllll}
\hline Call type & TOTAL & Spring & Summer & Autumn & Winter \\
\hline Theft & 7251 & 1719 & 2304 & 1944 & 1284 \\
Domestic dispute & 3713 & 895 & 1020 & 961 & 837 \\
Break and enter & 1887 & 386 & 586 & 534 & 381 \\
Assault & 1875 & 480 & 459 & 503 & 433 \\
Neighbor dispute & 1023 & 239 & 330 & 234 & 220 \\
Sum & 15,299 & 3719 & 4699 & 4176 & 3155 \\
\hline
\end{tabular}

2019). With this in mind, census polygons rather than a regular grid were chosen for this analysis. These polygons are defined by Statistics Canada based on areas of relatively homogenous socioeconomic characteristics, and are generally bounded by physical features such as roads and waterways. Specifically, both census tracts and dissemination areas were used for analysis (see Fig. 2) to better understand what impact, if any, scale would have on crime similarity as measured by the SPPT. There are 17 census tracts in the study area, with a mean size of 1883.7 ha, and 100 dissemination areas, with a mean size of 320.2 ha.

\section{Analytic strategy}

\section{Descriptive statistics and exploratory data analysis}

As a preliminary step, standard summary statistics relating to crime concentration were calculated for each call type in each season of the year. These statistics are the percentage of street segments in the study area which account for $50 \%$ of crime and the percentage of street segments for which any crime occurs. These statistics provide a first glimpse of whether, though not

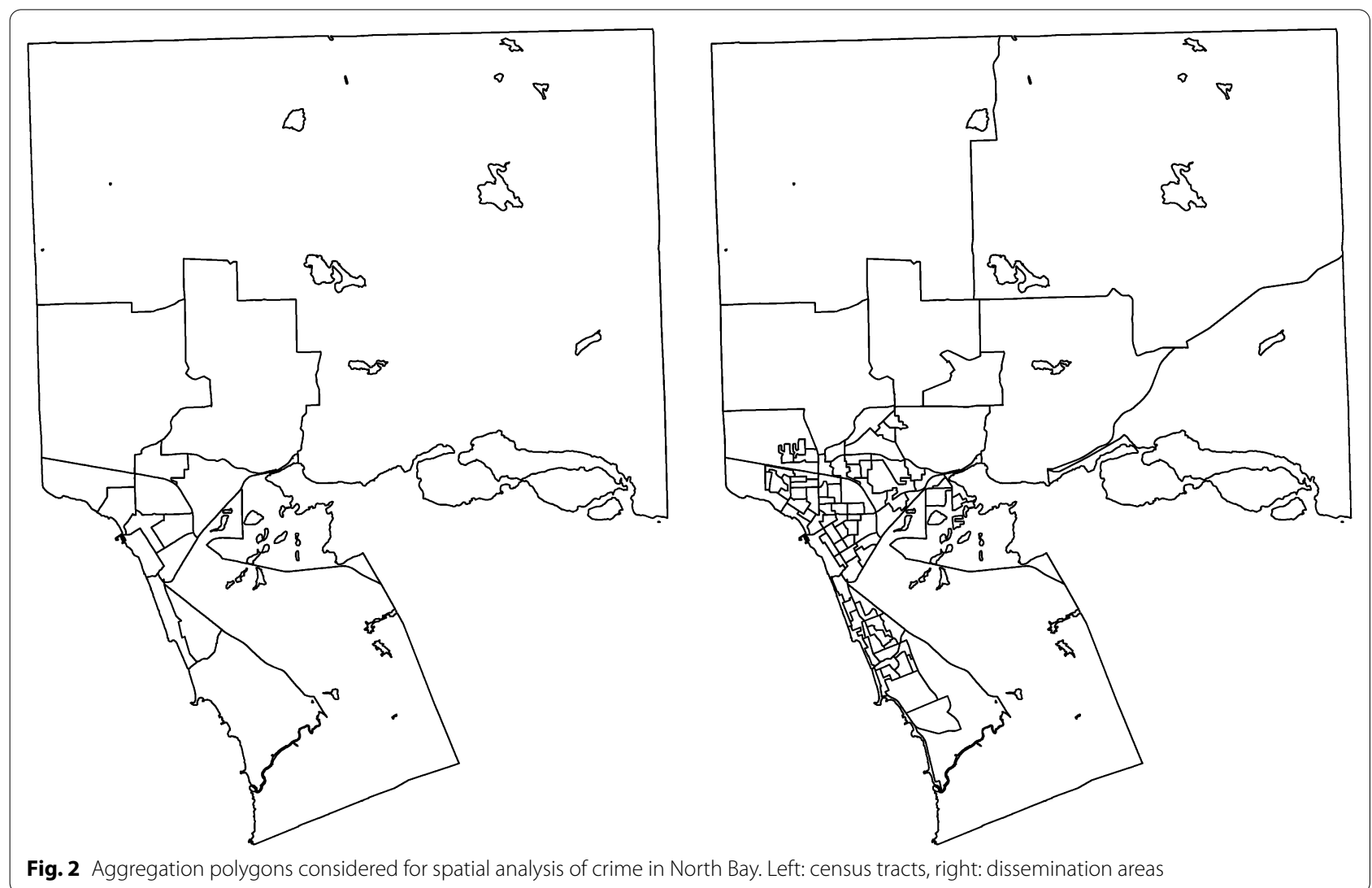


where, potential seasonal changes occur. They can also be interpreted in concert with later mapping for a fuller understanding of crime patterns in the study area.

To visualize seasonal crime patterns in North Bay, kernel density estimation (KDE) was used to map crime by season. This analysis was conducted in ArcMap 10.8 using a search radius of $650 \mathrm{~m}$ and a grid cell size of $10 \mathrm{~m}$ for all call types and all seasons in order to produce the most consistent maps possible. The resulting maps allow us to compare crime patterns on a visual basis without aggregating to polygons, thus avoiding the MAUP and revealing details that might be hidden at the coarser resolution of the aggregation polygons.

\section{Andresen's spatial point pattern test}

While visual examination of the kernel density maps provides some idea of whether crime patterns in North Bay differ between seasons, it is by nature subjective and cannot produce any numeric metric of similarity (Long \& Robertson, 2017). To produce such a metric, we employed the SPPT. All versions of this test compare two point patterns occurring within a set of aggregation units to produce both local and global measures of similarity (Andresen, 2016; Steenbeek \& Wheeler, 2020). For each aggregation unit, the most recent versions of the SPPT conducts a test of the difference in proportions of points occurring inside and outside of the unit in each pattern. If the proportion of points occurring within the aggregation unit is significantly different between patterns, this unit is considered to be dissimilar at the local level (Steenbeek \& Wheeler, 2020). Several difference in proportion tests are available; we chose to compare two versions, one which uses a bootstrap methodology and another which compares differences in proportions using Fisher's Exact Test.

To compute the global similarity statistic, or S Index, the SPPT assigns a value of 1 to those aggregation units considered similar between the two patterns, and a value of 0 to those considered dissimilar. It then calculates the average of these values across the study area, which is equivalent to the percentage of aggregation units in the study area displaying similarity (Andresen, 2009). A value of 0.80 or above is considered to indicate similarity in the study area as a whole (Andresen \& Linning, 2012). It is important to note that this is a rule of thumb; the index indicates the degree of similarity and is not useful in a binary context, such as determining whether the similarity of two patterns is statistically significant or not (Andresen, 2016).

For each call type, we used the SPPT to conduct pairwise comparisons between the point pattern occurring during each season of the year, and then produced maps to visualize the local differences in call patterns.

\section{Results}

Descriptive statistics and exploratory data analysis Crime concentration

The descriptive statistics calculated for the study area, presented in Table 4, indicate that crimes appear to occur at relatively few places in the city of North Bay. Of the call types under consideration, assault is most concentrated, while thefts are most widespread. Within crime types, concentration does vary somewhat between seasons, with calls being most dispersed during the summer. We do not apply significance testing to these values, but rather present them as an exploratory step in our data analysis.

\section{Spatial patterns of crime}

The kernel density maps can help to clarify whether the differences in concentration between the seasons constitute a change in intensity or a change in locations, and are presented here in order from most voluminous call type to least (Figs. 3, 4, 5, 6, 7). In general, all the chosen call types have a relatively consistent pattern, despite changes in intensity between the seasons. These calls are concentrated in the downtown area of the city and the adjacent residential area. Note that, while the seasonal maps within each call type use a common scale of density, the different call types do not use the same scale, so a high density of assaults does not indicate the same density of incidents as a high density of thefts.

Table 4 Crime concentration in North Bay, 2015-2019

\begin{tabular}{|c|c|c|c|c|c|c|c|c|}
\hline \multirow[t]{2}{*}{ Call type } & \multicolumn{4}{|c|}{$\%$ of street segments with any crime } & \multicolumn{4}{|c|}{$\%$ of all street segments accounting for $50 \%$ of crime } \\
\hline & Spring & Summer & Autumn & Winter & Spring & Summer & Autumn & Winter \\
\hline Theft & 22.74 & 29.37 & 26.79 & 17.63 & 2.98 & 4.22 & 4.01 & 2.16 \\
\hline Domestic dispute & 14.10 & 16.50 & 14.31 & 14.00 & 2.71 & 3.46 & 2.81 & 2.78 \\
\hline Break and enter & 9.09 & 13.34 & 11.87 & 9.19 & 2.50 & 3.70 & 3.19 & 2.64 \\
\hline Assault & 8.27 & 8.95 & 9.19 & 7.55 & 1.27 & 1.82 & 1.72 & 1.41 \\
\hline Neighbor Dispute & 4.84 & 6.72 & 5.35 & 5.11 & 1.30 & 1.65 & 1.34 & 1.37 \\
\hline
\end{tabular}




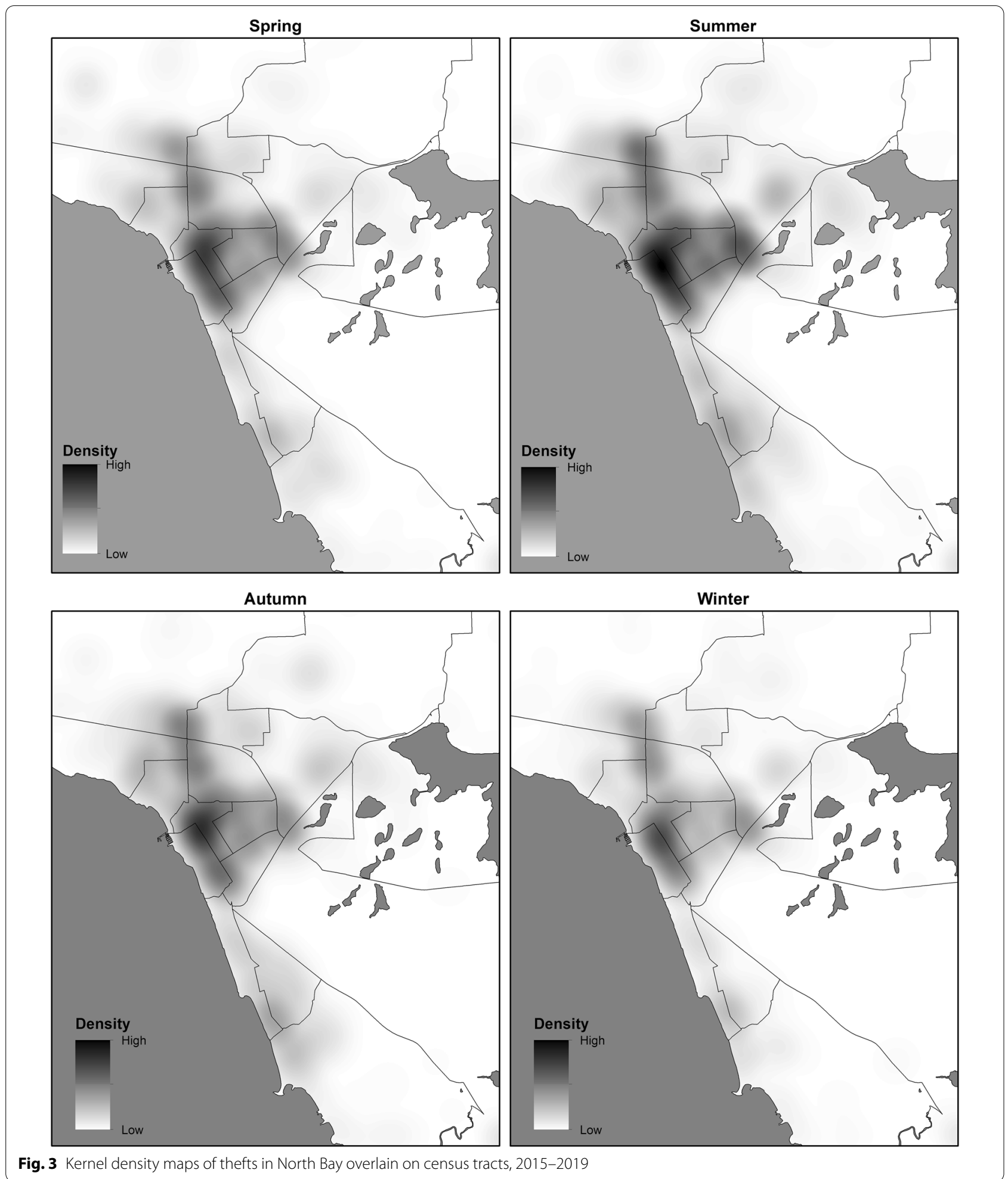

\section{Andresen's spatial point pattern test}

The bootstrap and the Fisher's Exact Test versions of the SPPT provide notably different results. The Fisher's
Exact version of the test appears to be more conservative, and produces a value of 1 , indicating perfect similarity between patterns, for the majority of comparisons. The $\mathrm{S}$ 


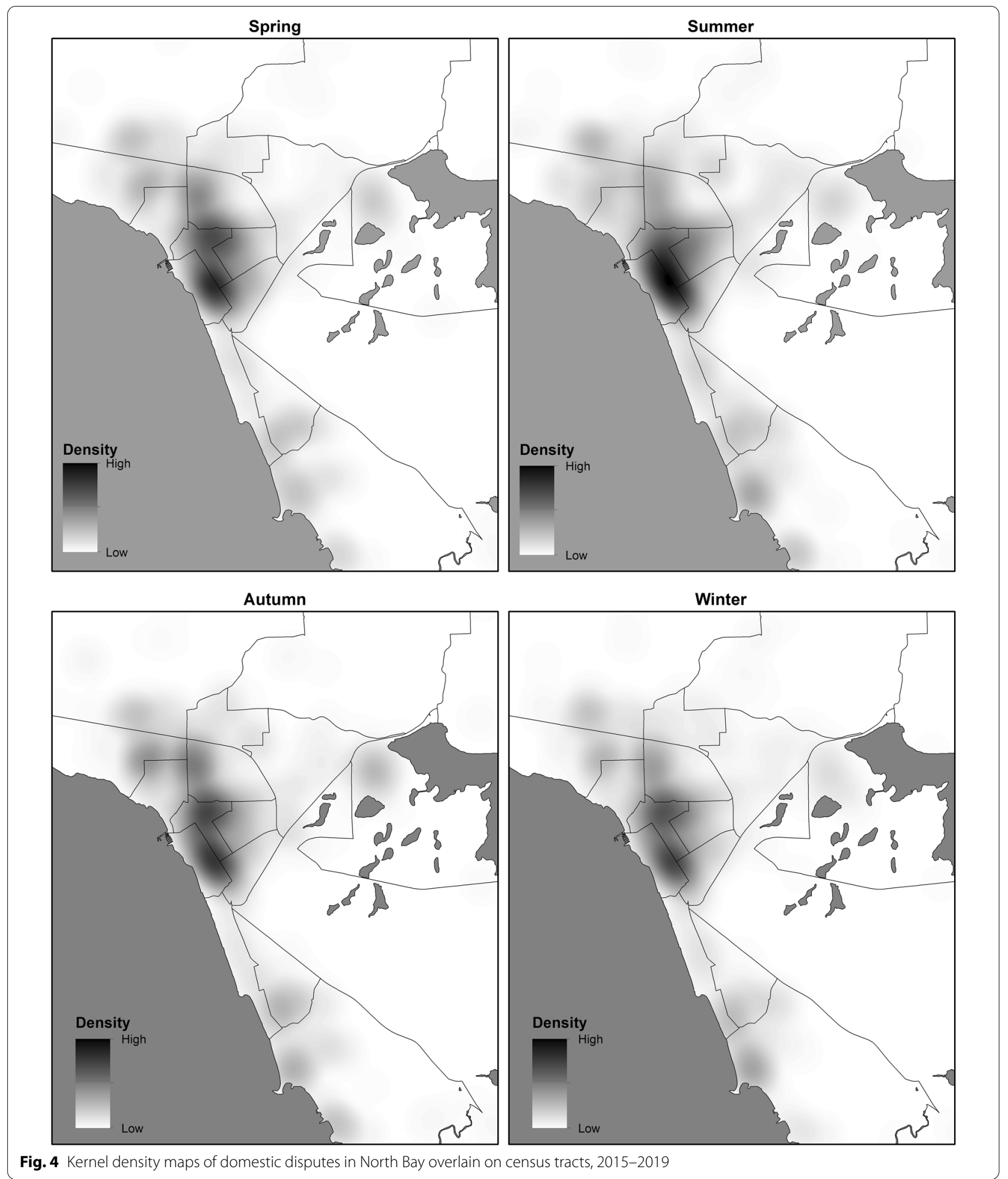

index values for those patterns not found to be perfectly similar are presented in Table 5. Even where the degree of similarity is not perfect, the $S$ Index still never reaches the rule of thumb value of 0.80 which would indicate a lack of similarity between the spatial patterns.

The results of the bootstrap version of the SPPT are less conservative, and rarely produce a result of perfect 


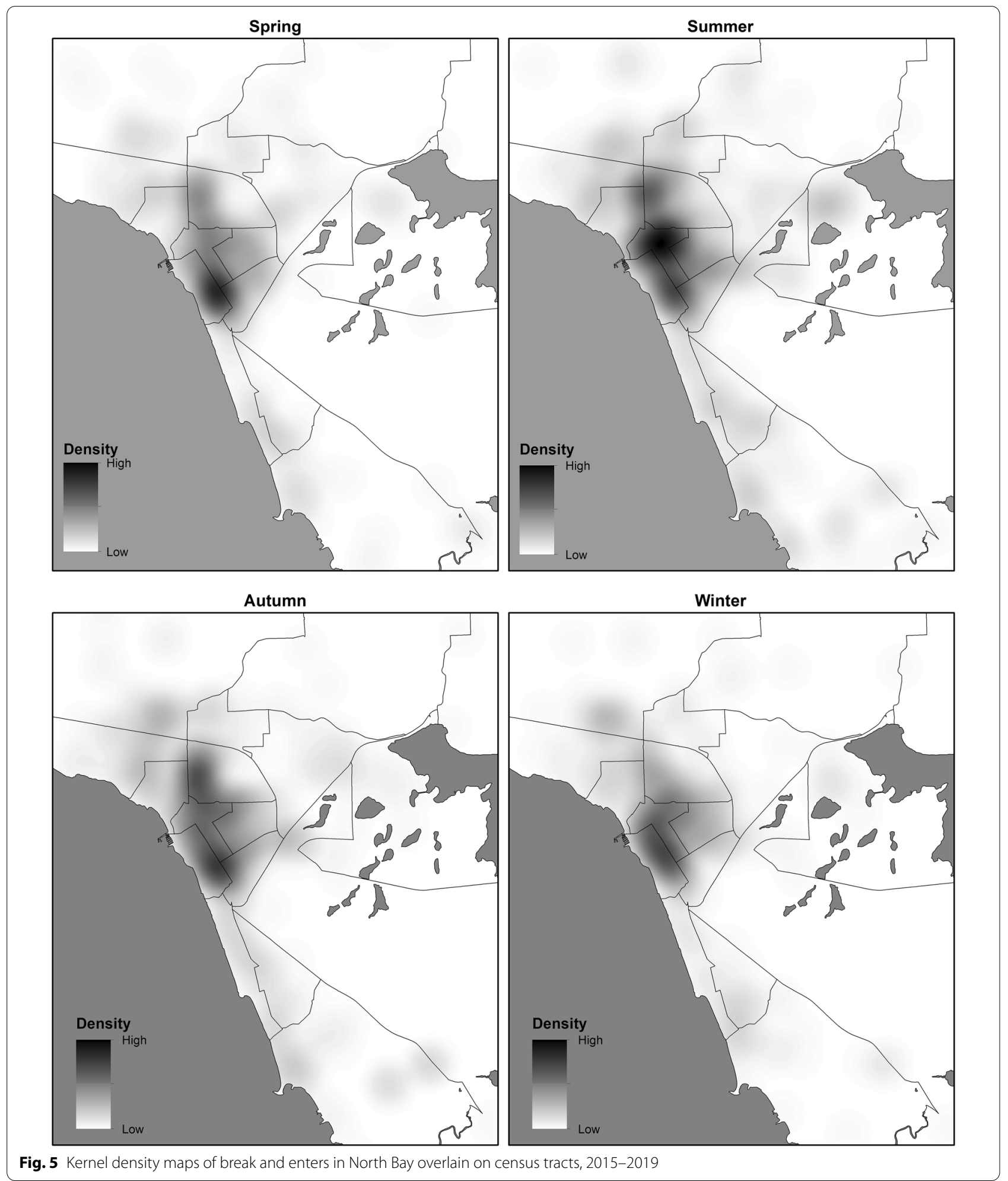

similarity even at the finer resolution of the dissemination area scale (Tables $6,7,8,9,10$ ). Despite this, the $\mathrm{S}$ index still does not reach a value of 0.80 in most cases.
The exceptions to this are for thefts, the pattern of which differs at the census tract scale in autumn as compared to both spring and winter (Table 6), and break and enters, 


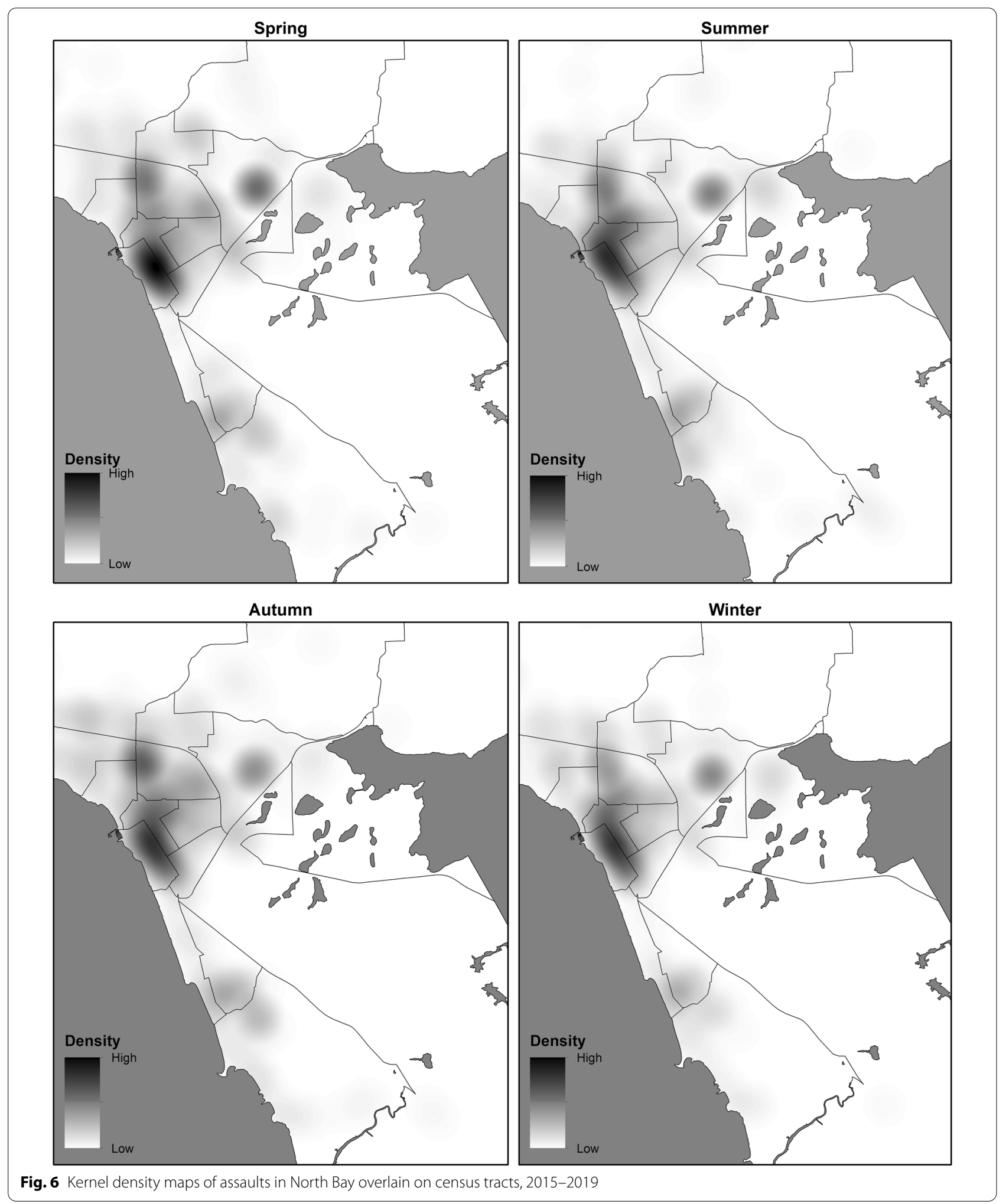




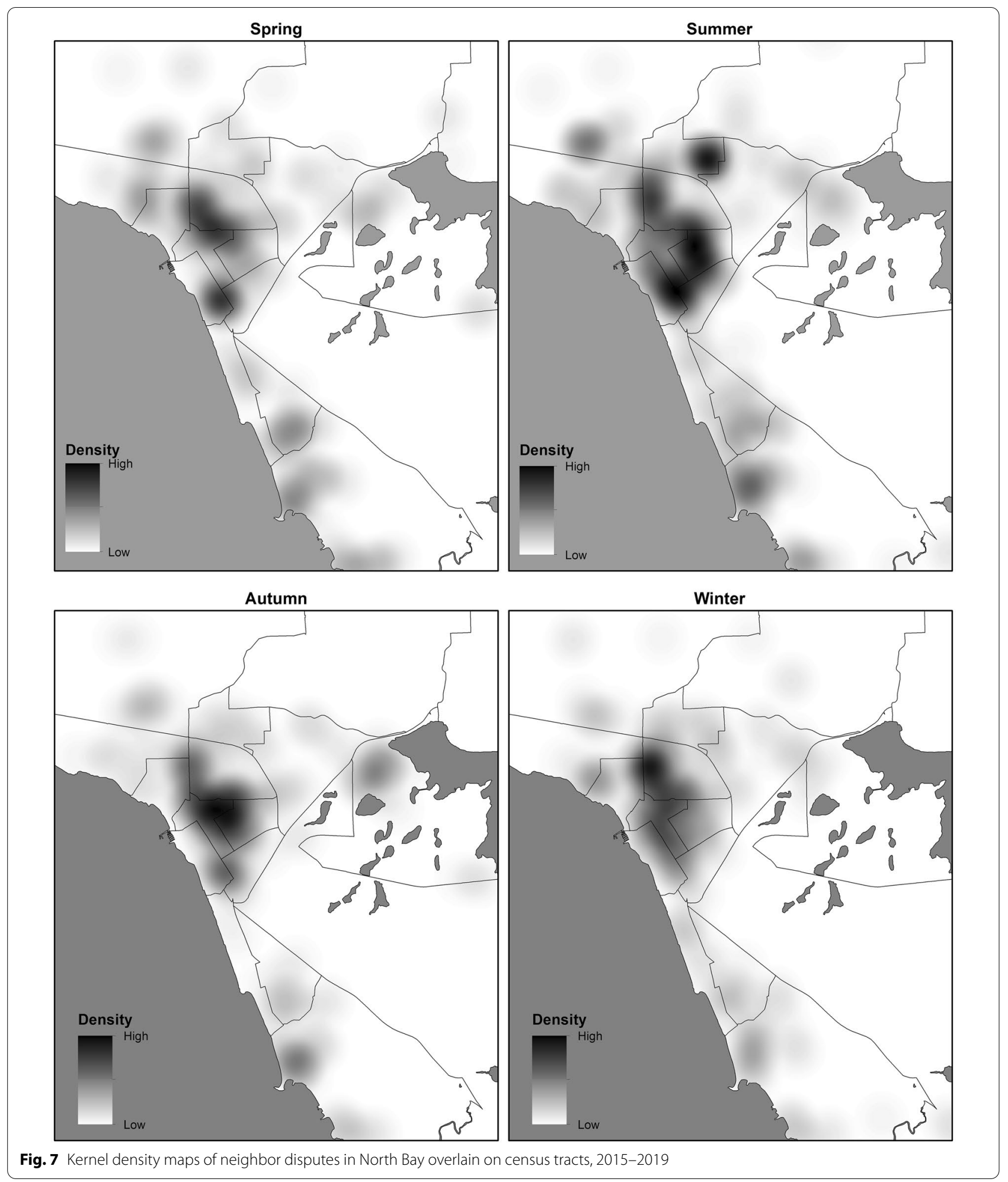


Table $5 \mathrm{~S}$ index for seasonal crime patterns indicating less than a perfect degree of similarity, based on Fisher's Exact Test SPPT

\begin{tabular}{llll}
\hline Call type & Seasons & Scale & S Index \\
\hline Break and enter & Summer vs. winter & Census tract & 0.941 \\
Theft & Summer vs. winter & Census tract & 0.882 \\
& Summer vs. winter & Census tract & 0.941 \\
& Summer vs. winter & Census tract & 0.941 \\
Neighbor dispute & Summer vs. winter & Census tract & 0.941 \\
& Summer vs. winter & Census tract & 0.941 \\
& Summer vs. autumn & Dissemination area & 0.989 \\
\hline
\end{tabular}

Table 6 S index for thefts, based on the bootstrap SPPT

\begin{tabular}{lllll}
\hline & Spring & Summer & Autumn & Winter \\
\hline Spring & & 0.94 & 0.76 & 0.88 \\
Summer & 0.94 & & 0.94 & 0.82 \\
Autumn & 0.93 & 0.88 & & 0.76 \\
Winter & 0.93 & 0.86 & 0.88 & \\
\hline
\end{tabular}

Top right: census tracts, bottom left: dissemination areas

Table $7 \mathrm{~S}$ index for domestic disputes, based on the bootstrap SPPT

\begin{tabular}{lllll}
\hline & Spring & Summer & Autumn & Winter \\
\hline Spring & & 0.94 & 0.88 & 1.00 \\
Summer & 0.94 & & 0.88 & 0.88 \\
Autumn & 0.94 & 0.87 & & 0.88 \\
Winter & 0.96 & 0.91 & 0.94 &
\end{tabular}

Top right: census tracts, bottom left: dissemination areas

Table $8 \mathrm{~S}$ index for break and enters, based on the bootstrap SPPT

\begin{tabular}{lllll}
\hline & Spring & Summer & Autumn & Winter \\
\hline Spring & & 0.88 & 0.82 & 1.00 \\
Summer & 0.87 & & 0.88 & 0.82 \\
Autumn & 0.93 & 0.89 & & 0.76 \\
Winter & 0.93 & 0.92 & 0.90 & \\
\hline
\end{tabular}

Top right: census tracts, bottom left: dissemination areas

Table 9 S index for assaults, based on the bootstrap SPPT

\begin{tabular}{lllll}
\hline & Spring & Summer & Autumn & Winter \\
\hline Spring & & 0.88 & 0.94 & 0.94 \\
Summer & 0.90 & & 0.88 & 0.88 \\
Autumn & 0.97 & 0.91 & & 0.94 \\
Winter & 0.95 & 0.94 & 0.95 & \\
\hline
\end{tabular}

Top right: census tracts, bottom left: dissemination areas
Table $10 \mathrm{~S}$ index for neighbor disputes, based on the bootstrap SPPT

\begin{tabular}{lllll}
\hline & Spring & Summer & Autumn & Winter \\
\hline Spring & & 0.94 & 0.82 & 0.94 \\
Summer & 0.88 & & 0.82 & 0.94 \\
Autumn & 0.93 & 0.94 & & 0.88 \\
Winter & 0.94 & 0.93 & 0.95 & \\
\hline
\end{tabular}

Top right: census tracts, bottom left: dissemination areas

which also differ in winter as compared to autumn (Table 8). Maps of local similarity based on the bootstrap SPPT are presented for call types and seasons whose global S index approaches 0.80 (Figs. 8, 9, 10, 11, 12, 13, 14, 15).

\section{Discussion \\ Crime concentration}

The crime concentration statistics summarized in Table 4 agree with Weisburd's law of crime concentration; crime in North Bay is concentrated at relatively few places. In addition, changes in crime concentration do appear to occur across the seasons for all of the chosen call types, which would imply a change in the locations of crimes. These calls are all least concentrated during the summer, indicating that crime occurs in a greater number of

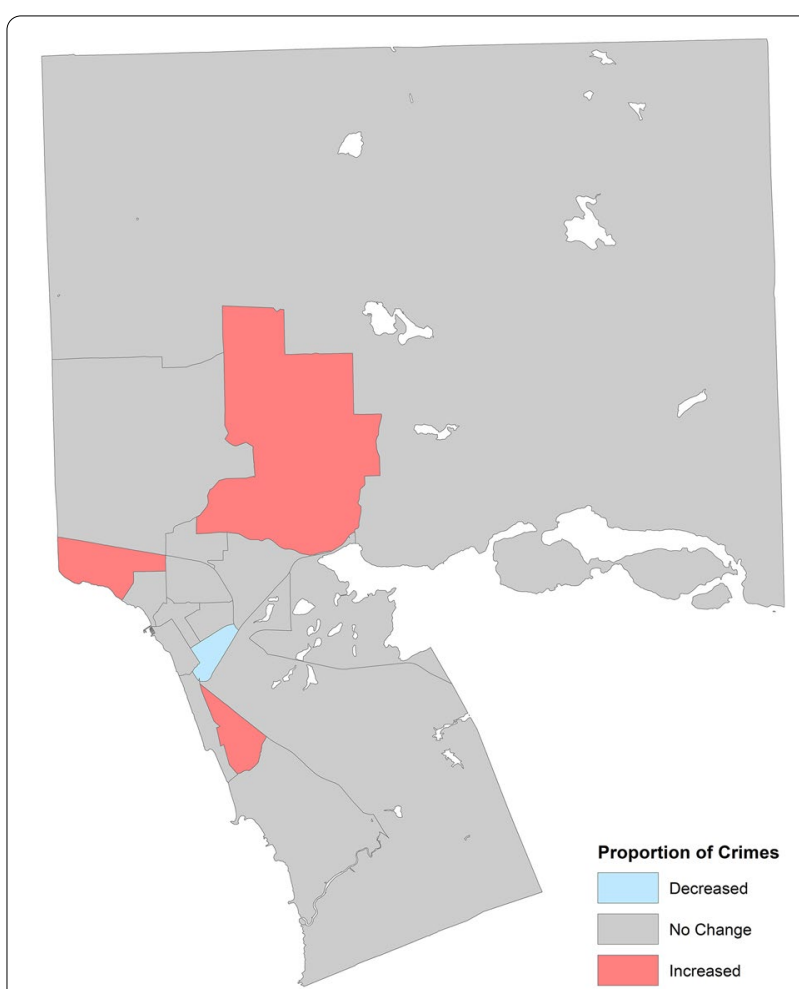

Fig. 8 Changes to the proportion of thefts occurring in North Bay in spring as compared to autumn 


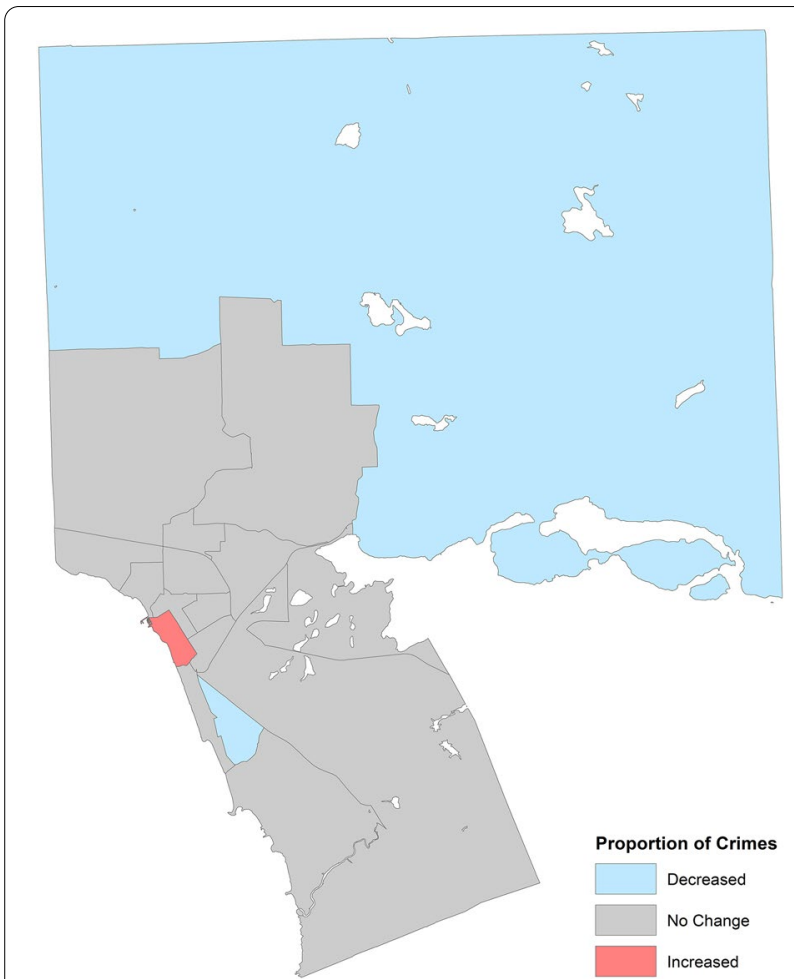

Fig. 9 Changes to the proportion of thefts occurring in North Bay in summer as compared to winter

places during this season. This finding is in line with routine activities theory, as people should be more likely to participate in outdoor leisure activities during the summer when the weather is hot, thus increasing their contact with others, and also the number of places that they visit. Both of these factors would increase not only the number of crimes, but also the number of places crimes occur.

\section{Spatial patterns of crime}

Some interesting trends are apparent in the kernel density mapping. First, all of the call types under consideration are concentrated in the downtown core of the city and adjacent densely populated neighborhoods (see Fig. 16), regardless of season. North Bay's downtown core is characterized by a mixture of small independent retailers and abandoned storefronts, with some housing. At the census tract level, it also incorporates the city's transit terminal, museum, library, and waterfront. The waterfront is a popular recreation area, and includes a marina, a bar, and extensive green spaces. Any of these features could attract people to visit the area, thus increasing both the pool of both potential offenders and victims, and

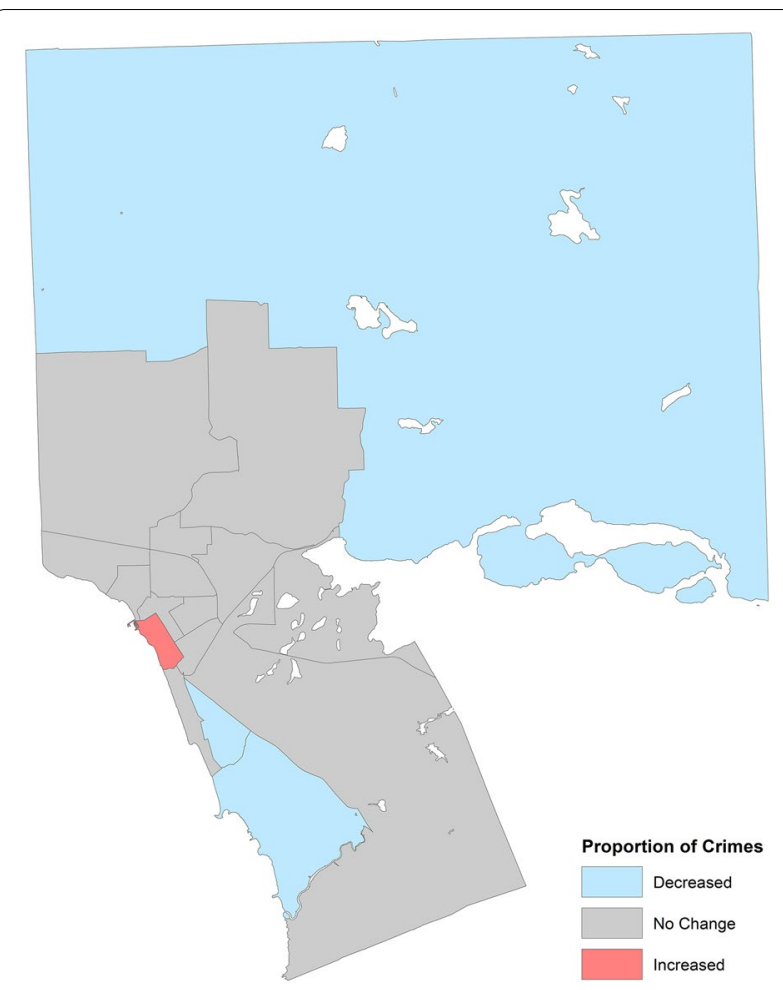

Fig. 10 Changes to the proportion of thefts occurring in North Bay in autumn as compared to winter

the number of crimes that occur. However, most of the aforementioned crime concentrations are inland from Lake Nipissing, and thus more likely to be associated with the main street than the waterfront and its recreational amenities. Given the large numbers of abandoned businesses downtown, this raises the possibility that broken windows theory is also at play (Welsh et al., 2015). This theory posits that physical and social disorder in a neighborhood increase fear, causing families to leave and other residents to isolate themselves, leading to a lack of social control and an increase in crime. A number of studies have shown that offenders operating in the vicinity of decayed or abandoned properties tend to worry less about the attention of police or residents (Valasik et al., 2019), whether or not this lack of concern stems from fear and isolation. Taken together, this would seem to indicate that there is a perceived lack of guardianship in areas with physical disorder, thus linking broken windows and routine activities theory.

In terms of seasonal trends, most of the hotspots visible in the density maps change in intensity over the seasons, but not in location. Additionally, these hotspots usually appear most intense during the summer. The 


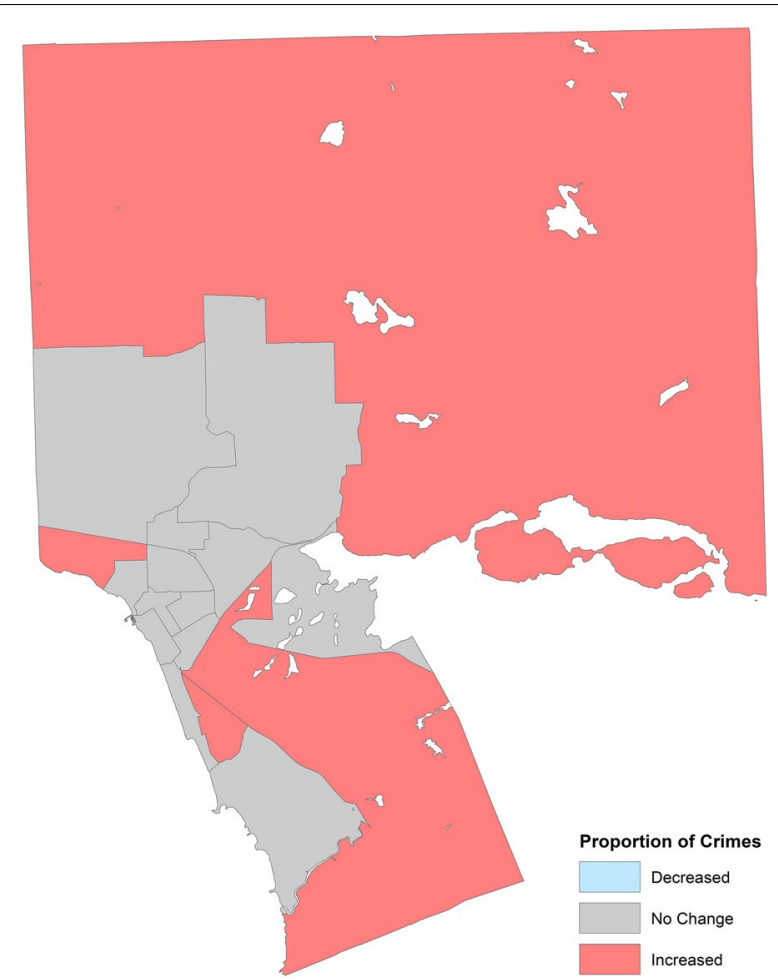

Fig. 11 Changes to the proportion of break and enters occurring in North Bay in spring as compared to autumn

exception to this summer increase in intensity is assaults, for which the downtown hotspot is slightly more intense in spring (Fig. 6). Interpreted along with the crime concentration statistics in Table 4, this suggests that while crime becomes more widespread in the summer, it is not spreading far, and those street segments that experience crime only during the summer are in roughly the same locations as those which experience crime year round. For thefts, assaults, and break and enters, this greater intensity of crime downtown during the warmer months of the year is in line with routine activities theory. As described in our discussion of crime concentration, this is the time of year when people should be most likely to participate in outdoor activities. Given the numerous suitable venues for such activities in the downtown core, it is unsurprising that this area might see more use, and therefore an increase in crime, during the summer. The same is not necessarily true of domestic disputes, however. These calls are by their nature more likely to occur when all participants are in the vicinity of their homes, and thus their increase is less amenable to explanation based on better weather during certain seasons. It is

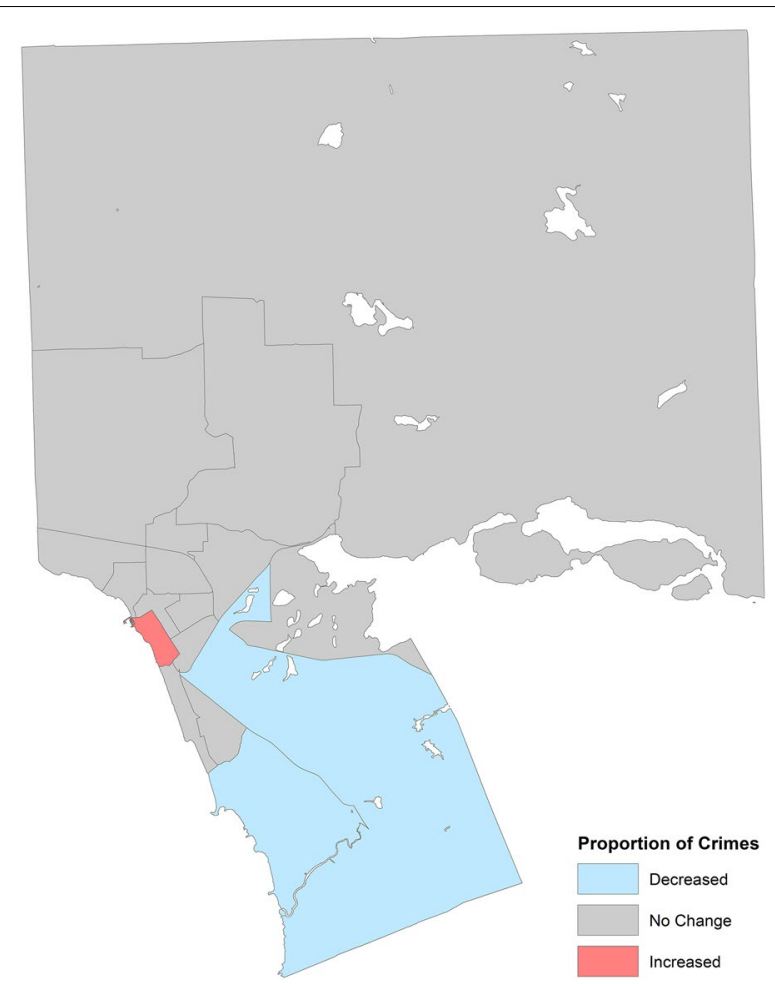

Fig. 12 Changes to the proportion of break and enters occurring in North Bay in summer as compared to winter

possible, however, that these disputes are simply more noticeable during the summer, either because they occur outside or because people are more likely to have their windows open. In this case, the summer increase in intensity of domestic disputes would simply represent a reporting bias.

Neighbor disputes are the only call type examined in this study which seem to exhibit a seasonal change in pattern. At first glance, the changes in neighbor disputes are as expected, in that an intense summer hotspot appears in the portion of downtown that contains the most homes, perhaps indicating that people are spending more time outside and thus have more opportunities to find fault with their neighbors. A similarly intense but more constrained hotspot also appears to the north east during this season. However, neighbor disputes presumably are most likely to occur between neighbors, that is, when all parties involved are in the vicinity of their homes. As such, there is no immediately apparent reason that they should form such distinct patterns during different seasons. There is no obvious reason, for example, that people living around 


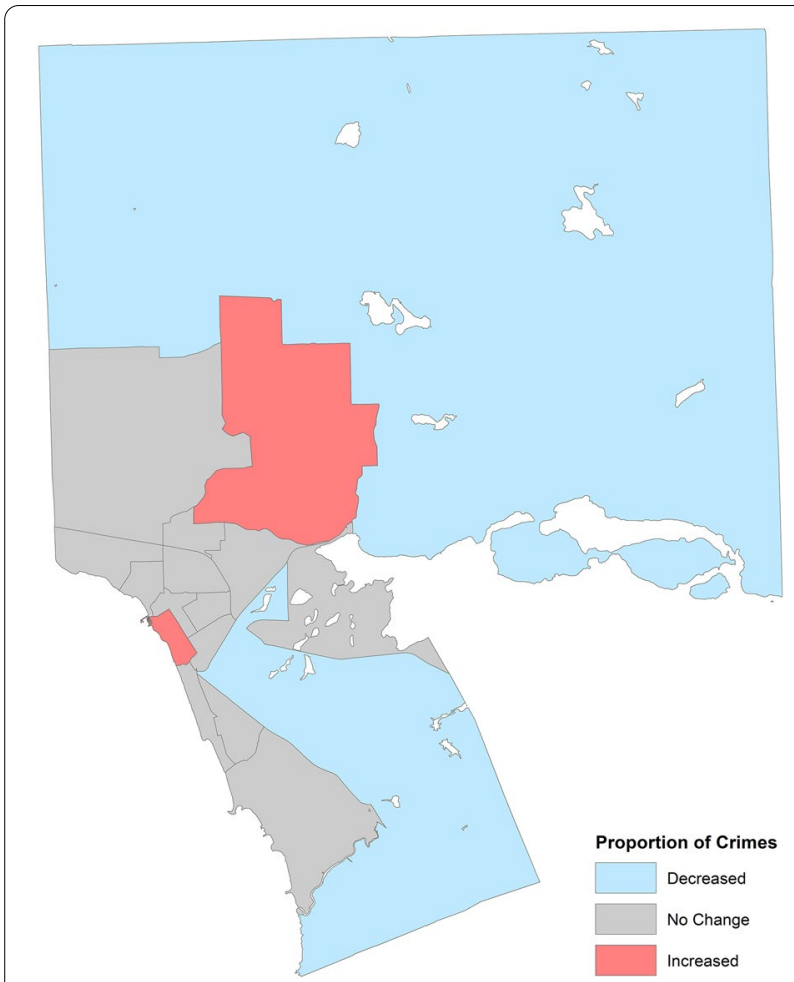

Fig. 13 Changes to the proportion of break and enters occurring in North Bay in autumn as compared to winter

the downtown core would spend more time outside during the summer than those from other parts of the city. Interestingly, downtown has some of the lowest incomes in the city (Fig. 17), which raises the possibility that this pattern is related to the socioeconomic status of the residents. Ceccato (2015) noted that crime patterns can change based on popular vacation times, when residents from wealthier areas tend to travel while those from poorer areas do not; while the cultural setting of this study was much different from North Bay, it is possible a similar effect is occurring here.

\section{Andresen's spatial point pattern test}

There are several trends apparent in the results of the SPPT, apart from the previously noted differences in degree of conservativeness between versions of the test. First, the census tracts do find decreased levels of similarity compared to the smaller dissemination areas. This is in line with the findings of several studies of Vancouver, where the larger aggregation units employed by Andresen and Malleson (2013) found considerably lower levels of similarity than the finer units used by Linning (2015).

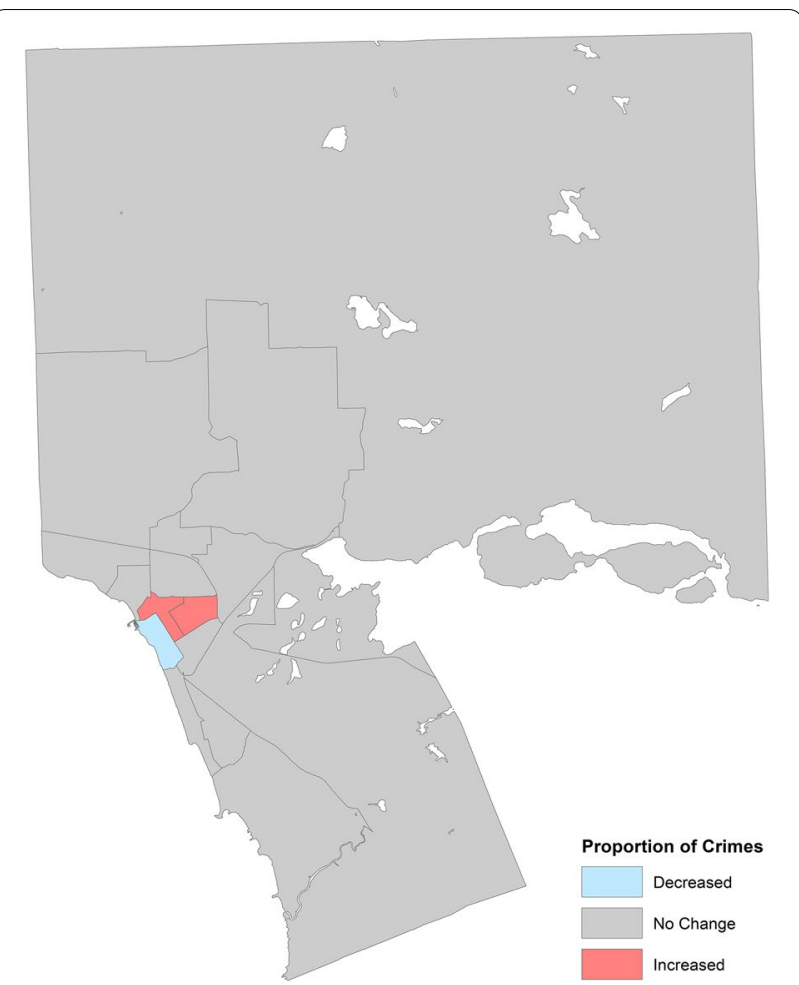

Fig. 14 Changes to the proportion of neighbor disputes occurring in North Bay in spring as compared to autumn

Second, certain areas of the city appear to be the particular focus of dissimilarity in seasonal crime patterns. The downtown core, for example, shows a significant decrease in calls during the winter as compared to other months, for both thefts and break and enters (Figs. 9, 10, 12 and 13). This is particularly notable because even the more conservative Fisher's Exact Test version of the SPPT was able to detect changes in the proportion of calls downtown. Moderately populated areas of the city (Fig. 16) tend not to exhibit seasonal changes in proportions of crime, while the less populated outlying areas of the city exhibit greater variability across a greater range of seasons. However, these changes are only apparent in the results of the bootstrap SPPT. The location of these changes, particularly for property crimes, is consistent with Linning's (2015) observations of motor vehicle theft in Ottawa, which similarly changed in intensity only in the downtown core. They are also consistent with Andresen and Malleson's (2013) results, which found increased levels of summer crime in Vancouver's central business district and other shopping areas. 


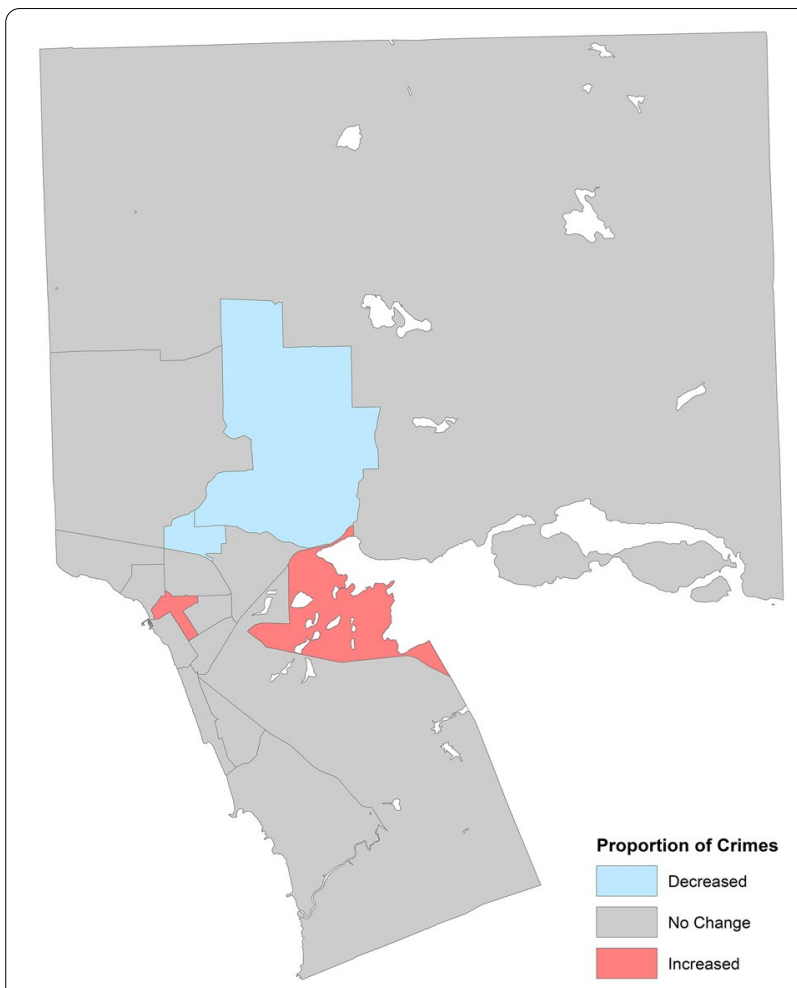

Fig. 15 Changes to the proportion of neighbor disputes occurring in North Bay in summer as compared to autumn

Routine activities theory has excellent potential to explain the increase in crimes in the city's downtown during the summer. Previous work suggests that the parks are most likely to be associated with summer increases in crime (Quick et al., 2019), and given North Bay's climate, it is logical that the outdoor recreational areas downtown as well as the main street are likely to see more use in the warmer, drier weather of summer. Further, this area is used to host various outdoor concerts and festivals during the summer; similar events in stadiums have been shown to act as crime generators, increasing crime counts in the areas that host them (Kurland et al., 2014). The school summer break might also play a role in increasing use of the downtown area during the summer (Cohn \& Rotton, 2000). This increased use would increase the likelihood of a potential offender and a suitable victim intersecting in time and space, although it should also increase the presence of capable guardianship. As previously noted, the socioeconomic characteristics of the downtown core may also have an impact. Sorg and Taylor (2011) link low socioeconomic status to increased seasonality in street robberies in a neighborhood, and while robbery is by definition a violent crime, it also involves an element of property acquisition, and thus provides an interesting parallel to the seasonality of thefts in downtown North Bay.

The changes in the outlying areas of the city are less intuitive to explain. For break and enters, several large census tracts experience a decrease in calls during autumn, as compared to both winter (Fig. 13) and spring (Fig. 11). Both of these tracts are very sparsely populated, consisting of a mixture of rural residential and commercial properties. Key phenomena that are associated with autumn in North Bay are cooler temperatures, the end of summer vacation time, and hunting season. Cooler temperatures seem unlikely to influence use of these areas of the city, given the lack of facilities whose use is weather dependent. However, the end of the summer vacation could decrease the pool of potential offenders in these areas, while hunting season might increase guardianship, providing a potential routine activities explanation for this observed pattern.

The pattern is a little different for thefts; these appear to increase in the largest northern census tract during winter, as compared to both autumn (Fig. 10) and summer (Fig. 9). This is again less obviously explicable by the routine activities theory, which generally posits a decrease in crime during less favorable weather. However, winter in North Bay actually sees an increase in accessibility to remote areas, as a large network of official and unofficial snowmobile trails is in operation in outlying areas of the city at this time of year. This could both increase the pool of potential offenders in remote areas, and open up new areas to their use. Another interesting change in thefts occurs in the wedge shaped census tract just south of the downtown core. This tract is almost entirely residential, but does include a strip mall with a movie theatre, grocery store, and several bargain shops. The kernel density mapping (Fig. 3) suggests that it is this commercial area of the tract which generates the most theft calls, in all seasons of the year. According to the SPPT mapping, these thefts decrease in autumn as compared to both spring (Fig. 8) and winter (Fig. 10), but increase in winter as compared to summer (Fig. 9). The decrease in autumn can be explained in a similar way to the change in break and enters, as a function of the end of summer vacation and thus a decrease in the pool of potential offenders with leisure time to spare. However, the summer decrease would appear to be at odds with this explanation.

It is worth noting that neighbor disputes do not follow the general pattern described above, but rather increase in the area around but outside of the downtown core, in both spring (Fig. 14) and summer (Fig. 15) as compared 


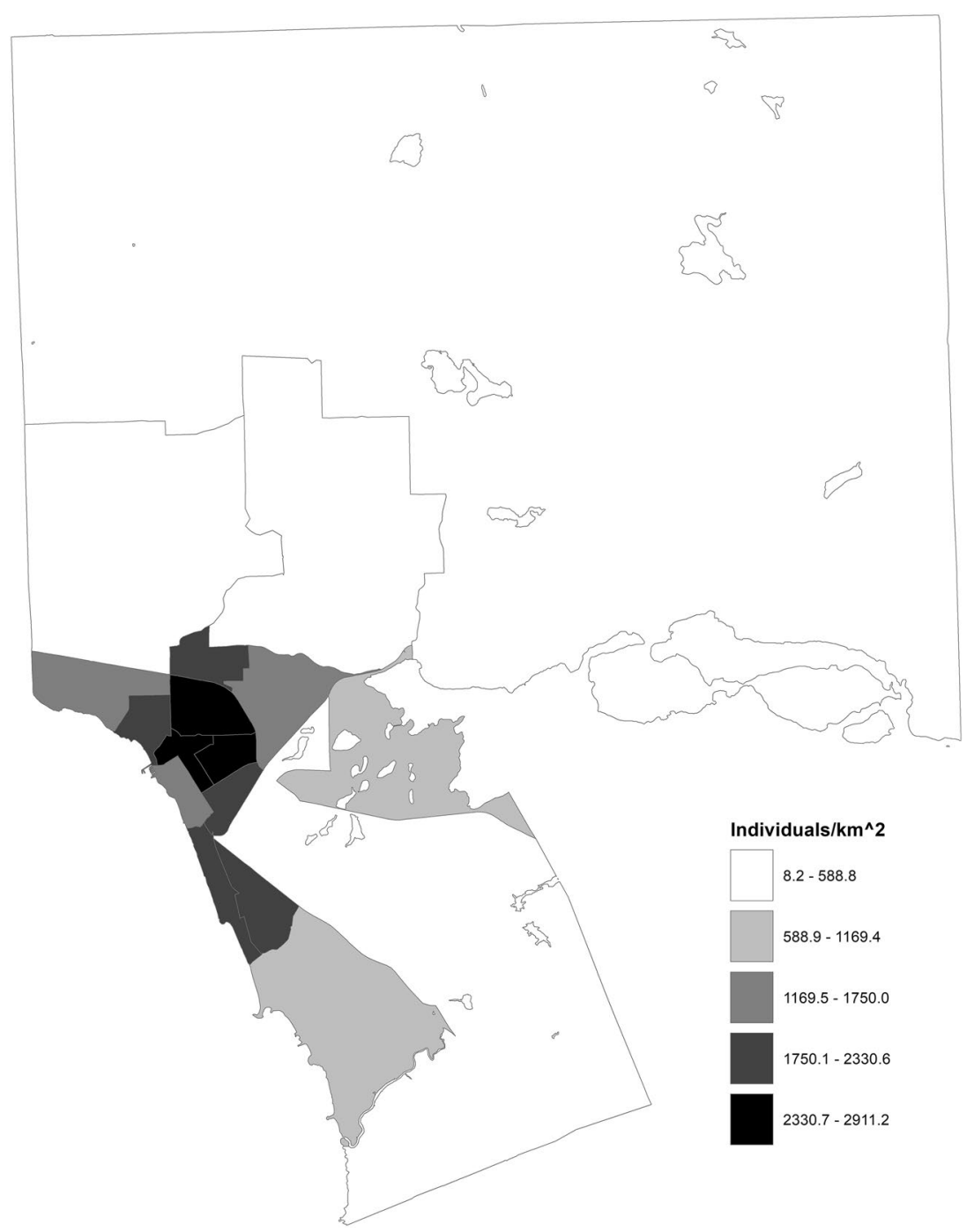

Fig. 16 Population density in North Bay census tracts, 2016. With data from Statistics Canada

to autumn. The results of the SPPT for this call type are logical, in that neighbor disputes are likely to occur in the vicinity of the disputants' homes, and the results show significant changes in some of the most densely populated areas of the city, at times of year when people are more likely to be outside or to have their windows open, and thus may be more likely to come into conflict with their neighbors. Further, the SPPT results agree with the patterns that are visible in the kernel density mapping (Fig. 7).

In general, the results of this analysis are as expected, with differences in seasonal pattern constrained to certain areas of the city and certain call types, and can be explained by the routine activities theory. It is notable, however, that assaults do not appear to display any seasonal change in pattern; these crimes are less likely to be committed based on the physical characteristics of a location than thefts or break and enters, and thus should be more mobile (Linning, 2015). Notably, these are among the least voluminous of our call types, and given the theoretically unexpected results, there are some concerns regarding small sample size. Andresen and Malleson (2014) encountered similar problems in their analysis of crime displacement in a small study area, using an earlier version of the SPPT, and attribute the unexpectedly high similarity for some crime types to low incident counts. While the results for neighbor disputes, which are even less frequent than assaults, do mitigate this concern 


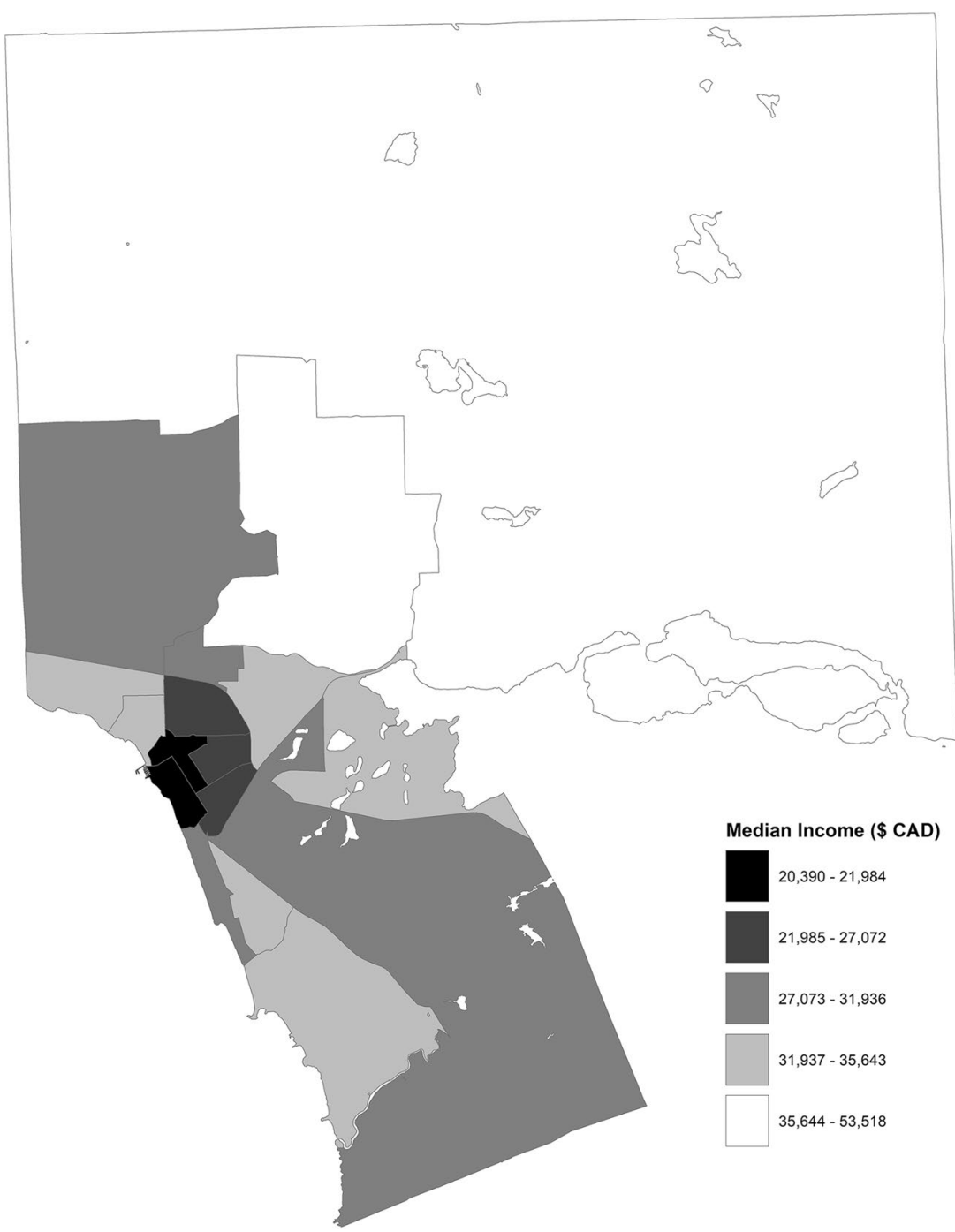

Fig. 17 Median income in North Bay census tracts, 2015. With data from Statistics Canada

somewhat in our analysis, further research in small cities and validation of the results based on other techniques would be of great benefit.

\section{Conclusions}

This study aimed to determine whether the spatial patterns of selected crime types change on a seasonal basis in a small northern Ontario city, the first such investigation in a study area of this size. Summary statistics, visual comparison of density maps, and analysis using the SPPT suggest that crime locations do not change to any great degree between the seasons. Some methodological considerations also emerged from this analysis, which may be of benefit to other researchers with small study areas. First, the Fisher's Exact Test version of the SPPT is very conservative, resulting in findings of perfect similarity in many comparisons. As such, it may be preferable to employ the bootstrap version of the test if there is no theoretical reason to avoid doing so. Second, use of smaller aggregation units also result in a lower degree of similarity. This may exacerbate issues with low incident counts, particularly in small study areas, and thus careful consideration should be given to the trade-off between these problems and the increased spatial resolution offered by smaller aggregation units.

\section{Abbreviations}

NBPS: North Bay Police Service; SPPT: Spatial point pattern test; MAUP: Modifiable areal unit problem; KDE: Kernel density estimation.

\section{Acknowledgements}

The authors would like to Mr. W. Scott Tod, Chief of Police, North Bay Police Service, for providing the data and Dr. David Zarifa, Department of 
Sociology, Nipissing University, for his suggestions and edits of the submitted manuscript.

\section{Authors' contributions}

YAC contributed to the design of the study, carried out the analysis, generated the visuals, and prepared the manuscript. JMK worked with community partners to obtain access to the data, contributed to the design of the study and contributed to the final version of the submitted manuscript. Both authors read and approved the final manuscript.

\section{Funding}

The authors declare no funding.

\section{Availability of data and materials}

Data for this article is not publically available at the request of the North Bay Police Service, due to privacy concerns.

\section{Declarations}

\section{Competing interests}

The authors declare that they have no competing interests.

Received: 21 July 2021 Accepted: 17 October 2021

Published online: 26 October 2021

\section{References}

Andresen, M. A. (2009). Testing for similarity in area-based spatial patterns: A nonparametric Monte Carlo approach. Applied Geography, 29, 333-345. https://doi.org/10.1016/j.apgeog.2008.12.004

Andresen, M. A. (2016). An area-based nonparametric spatial point pattern test: The test, its applications, and the future. Methodological Innovations, 9, 1-11. https://doi.org/10.1177/2059799116630659

Andresen, M. A., \& Linning, S. J. (2012). The (in)appropriateness of aggregating across crime types. Applied Geography, 35, 275-282. https://doi.org/10. 1016/j.apgeog.2012.07.007

Andresen, M. A., \& Malleson, N. (2013). Crime seasonality and its variations across space. Applied Geography, 43, 25-35. https://doi.org/10.1016/j. apgeog.2013.06.007

Andresen, M. A., \& Malleson, N. (2014). Police foot patrol and crime displacement: A local analysis. Journal of Contemporary Criminal Justice, 30(2), 186-199. https://doi.org/10.1177/1043986214525076

BayToday Staff. (2019). Crime in North Bay getting worse says MacLean's study. BayToday. https://www.baytoday.ca/local-news/crime-in-north-bay-getti ng-worse-says-macleans-study-1875502

Bernasco, W., \& Block, R. (2011). Robberies in Chicago: A block-level analysis of the influence of crime generators, crime attractors, and offender anchor points. Journal of Research in Crime and Delinquency, 48(1), 33-57. https:// doi.org/10.1177/0022427810384135

Brantingham, P. L., \& Brantignham, P. J. (1993). Nodes, paths and edges: Considerations on the complexity of crime and the physical environment. Journal of Environmental Psychology, 13, 3-28. https://doi.org/10.1016/ S0272-4944(05)80212-9

Breetzke, G. D., \& Cohn, E. G. (2012). Seasonal assault and neighbourhood deprivation in South Africa: Some preliminary findings. Environment and Behavior, 44(5), 641-667. https://doi.org/10.1177/0013916510397758

Brower, A. M., \& Carroll, L. (2007). Spatial and temporal aspects of alcoholrelated crime in a college town. Journal of American College Health, 55(5), 267-275. https://doi.org/10.3200/JACH.55.5.267-276

Brunsdon, C., Corcoran, J., Higgs, G., \& Ware, A. (2009). The influence of weather on local geographic patterns of police calls for service. Environment and Planning B: Urban Analytics and City Science, 36(5), 90-97. https://doi.org/ $10.1068 /$ b32133

Buil-Gil, D., Moretti, A., \& Langton, S. H. (2021). The accuracy of crime statistics: Assessing the impact of police data bias on geographic crime analysis. Journal of Experimental Criminology. https://doi.org/10.1007/ s11292-021-09457-y
Campaigne, S. (2021). Petition seeks change for North Bay 'under siege'. BayToday. https://www.baytoday.ca/local-news/petition-seeks-changefor-north-bay-under-siege-3765697

Ceccato, V. (2005). Homicide in Sao Paulo, Brazil: Assessing spatial-temporal and weather variations. Journal of Environmental Psychology, 25(3), 307-321. https://doi.org/10.1016/j.jenvp.2005.07.002

Cohen, L. E., \& Felson, M. (1979). Social change and crime rate trends: A routine activity approach. American Sociological Review, 44(4), 588-608. https:// doi.org/10.2307/2094589

Cohn, E. G. (1990). Weather and crime. British Journal of Criminology, 30(1), 51-64. https://doi.org/10.1093/oxfordjournals.bjc.a047980

Cohn, E. G., \& Rotton, J. (2000). Weather, seasonal trends and property crimes in Minneapolis, 1987-1988. A moderator-variable time-series analysis of routine activities. Journal of Environmental Psychology, 20(3), 257-272. https://doi.org/10.1006/jevp.1999.0157

de Melo, S. N., Pereira, D. V. S., Andresen, M. A., \& Matias, L. F. (2018). Spatial/ temporal variations of crime: A routine activity theory perspective. International Journal of Offender Therapy and Comparative Criminology, 62(7) 1967-1991. https://doi.org/10.1177/0306624X17703654

Federal Economic Development Agency for Northern Ontario. (2018). Prosperity and Growth Strategy for Northern Ontario. https://fednor.gc.ca/eic/site/ fednor-fednor.nsf/vwapj/PGSNO-2018.pdf/\$file/PGSNO-2018.pdf

Gerell, M. (2017). Smallest is better? The spatial distribution of arson and the modifiable areal unit problem. Journal of Quantitative Criminology, 33, 293-318. https://doi.org/10.1007/s10940-016-9297-6

Haberman, C. P., Sorg, E. T., \& Ratcliffe, J. H. (2018). The seasons they are a changin': Testing for seasonal effects of potentially criminogenic places on street robbery. Journal of Research in Crime and Delinquency, 55(3), 425-459. https://doi.org/10.1177/0022427818758375

Hipp, J. R. (2007). Block, tract, and levels of aggregation: Neighbourhood structure and crime and disorder as a case in point. American Sociological Review, 72(5), 659-680. https://doi.org/10.1177/000312240707200501

Kurland, J., Johnson, S. D., \& Tilley, N. (2014). Offences around stadiums: A natural experiment on crime attraction and generation. Journal of Research in Crime and Delinquency, 51(1), 5-28. https://doi.org/10.1177/0022427812 471349

Linning, S. J. (2015). Crime seasonality and the micro-spatial patterns of property crime in Vancouver, BC and Ottawa ON. Journal of Criminal Justice, 43(6), 544-555. https://doi.org/10.1016/j.jcrimjus.2015.05.007

Linning, S. J., Andresen, M. A., \& Brantingham, P. J. (2017). Crime seasonality: Examining the temporal fluctuations of property crime in cities with varying climates. International Journal of Offender Therapy and Comparative Criminology, 61(16), 1866-1891. https://doi.org/10.1177/0306624X16 632259

Long, J., \& Robertson, C. (2017). Comparing spatial patterns. Geography Compass. https://doi.org/10.1111/gec3.12356

Malleson, N., Steenbeek, W., \& Andresen, M. A. (2019). Identifying the appropriate spatial resolution for the analysis of crime patterns. PLOS ONE. https:// doi.org/10.1371/journal.pone.0218324

McDowall, D., Loftin, C., \& Pate, M. (2012). Seasonal cycles in crime, and their variability. Journal of Quantitative Criminology, 28(3), 389-410. https://doi. org/10.1007/s10940-011-9145-7

Pickrell, A. (2020). Recent crime victims speak out as North Bay Police Service announces new Community Response Unit. CTV News. https://north ernontario.ctvnews.ca/recent-crime-victims-speak-out-as-north-baypolice-service-announces-new-community-response-unit-1.5157648

Quick, M., Law, J., \& Li, G. (2019). Time-varying relationships between land use and crime: A spatio-temporal analysis of small-area seasonal property crime trends. Environment and Planning B: Urban Analytics and City Science, 46(6), 1018-1035. https://doi.org/10.1177/2399808317744779

Ranson, M. (2014). Crime, weather, and climate change. Journal of Environmental Economics and Management, 67(3), 274-302. https://doi.org/10.1016/j. jeem.2013.11.008

Ratcliffe, J. H., \& McCullagh, M. J. (1999). Hotbeds of crime and the search for spatial accuracy. Journal of Geographical Systems, 1, 385-398. https://doi. org/10.1007/s101090050020

Sorg, E. T., \& Taylor, R. B. (2011). Community-level impacts of temperature on urban street robbery. Journal of Criminal Justice, 39, 463-470. https://doi. org/10.1016/j.jcrimjus.2011.08.004

Statistics Canada. (2017). North Bay census profile (Catalogue number 98-3316-X2016001). 2016 Census. https://www12.statcan.gc.ca/ 
census-recensement/2016/dp-pd/prof/details/page.cfm?Lang=E\& Geo1=POPC\&Code1 $=0595 \&$ Geo2=PR\&Code2=35\&SearchText $=$ North\% 20Bay\&SearchType $=$ Begins\&SearchPR $=01 \& B 1=$ All\&GeoLevel $=P R \&$ GeoCode $=0595 \& \mathrm{TABID}=1 \&$ type $=0$

Steenbeek, W. \& Wheeler, A. (2020). Proportion difference tests. sppt. http:// htm/preview.github.io/?https://github.com/wsteenbeek/sppt/blob/ master/doc/sppt_diff.html

Szkola, J., Piza, E. L., \& Drawve, G. (2019). Risk terrain modeling: Seasonality and predictive validity. Justice Quarterly. https://doi.org/10.1080/07418825. 2019.1630472

Trenberth, K. E. (1983). What are the seasons. Bulletin of the American Meteorological Society, 64(11), 1276-1282. https://doi.org/10.1175/15200477(1983)064\%3c1276:WATS\%3e2.0.CO;2

Valasik, M., Brault, E. E., \& Martinez, S. M. (2019). Forecasting homicide in the red stick: Risk terrain modeling and the spatial influence of urban blight on lethal violence in Baton Rouge, Louisiana. Social Science Research, 80, 186-201. https://doi.org/10.1016/j.ssresearch.2018.12.023

Vandeviver, C., \& Steenbeek, W. (2019). The (in)stability of residential burglary patterns on street segments: The case of Antwerp, Belgium 2005-2016.
Journal of Quantitative Criminology, 35, 111-133. https://doi.org/10.1007/ s10940-017-9371-8

Weisburd, D. (2015). The law of crime concentration and the criminology of place. Criminology, 53(2), 133-157. https://doi.org/10.1111/1745-9125. 12070

Welsh, B. C., Braga, A. A., \& Bruinsma, J. N. (2015). Reimagining broken windows: From theory to policy. Journal of Research in Crime and Delinquency, 52(4), 447-463. https://doi.org/10.1177/0022427815581399

Yiannakoulias, N., \& Kielasinka, E. (2016). The effect of temperature on arson incidence in Toronto, Ontario, Canada. International Journal of Biometeorology, 60, 651-661. https://doi.org/10.1007/s00484-015-1059-x

\section{Publisher's Note}

Springer Nature remains neutral with regard to jurisdictional claims in published maps and institutional affiliations.
Ready to submit your research? Choose BMC and benefit from:

- fast, convenient online submission

- thorough peer review by experienced researchers in your field

- rapid publication on acceptance

- support for research data, including large and complex data types

- gold Open Access which fosters wider collaboration and increased citations

- maximum visibility for your research: over $100 \mathrm{M}$ website views per year

At BMC, research is always in progress.

Learn more biomedcentral.com/submissions 